\title{
Los Sigchos, el último refugio de los incas quiteños. Una propuesta preliminar
}

\section{Tamara Estupiñán Viteri}

\section{(2) OpenEdition}

\section{Journals}

Edición electrónica

URL: http://journals.openedition.org/bifea/1684

DOI: $10.4000 /$ bifea. 1684

ISSN: 2076-5827

Editor

Institut Français d'Études Andines

Edición impresa

Fecha de publicación: 1 abril 2011

Paginación: 191-204

ISSN: 0303-7495

\section{Referencia electrónica}

Tamara Estupiñán Viteri, «Los Sigchos, el último refugio de los incas quiteños. Una propuesta preliminar », Bulletin de l'Institut français d'études andines [En línea], 40 (1) | 2011, Publicado el 01 octubre 2011, consultado el 10 diciembre 2020. URL : http://journals.openedition.org/bifea/1684 ; DOI : https://doi.org/10.4000/bifea.1684

\section{cc)}

Les contenus du Bulletin de l'Institut français d'études andines sont mis à disposition selon les termes de la licence Creative Commons Attribution - Pas d'Utilisation Commerciale - Pas de Modification 4.0 International. 


\title{
Los Sigchos, el último refugio de los incas quiteños Una propuesta preliminar
}

\author{
Tamara Estupiñán Viteri*
}

\section{INTRODUCCIÓN}

Estudiar a Rumiñahui, el hombre más leal a Atahualpa y el principal líder de la resistencia del Quito-Inca contra los conquistadores españoles, ha sido un desafío para mí.

Durante casi una década he pasado escudrinando en distintos archivos y bibliotecas, transcribiendo documentos y analizando las diferentes lecturas acerca de su proceder. También he buscado de montaña en montaña otras pistas que me ayuden a descifrar por qué Rumiñahui, sin ser un inca de nobleza pero sí de privilegio, en un momento de drama, desesperación y caos, pudo organizar un ejército compuesto por incas y por varias naciones locales de poco más o menos 50000 hombres para enfrentarse a los conquistadores españoles y los indios aliados, con lo cual evitó, además, la segmentación política inmediata de esos territorios. Rumiñahui, fue igualmente reconocido por los parientes más cercanos de Atahualpa, entre ellos Zopozo Pangue, tío del monarca y gobernador del Quito-Inca, quien tenía mayor rango militar que él, o Calicuchima, jefe máximo de los ejércitos de los incas quiteños, o Quisquis, el militar inca quiteño más célebre en la toma del Cusco, o Quimbalimbo, Tucomango, Ninanina y Rasoraso, caciques y líderes de las naciones locales, así como por los grupos subalternos de mitimáes e indios.

Becaria del Instituto Francés de Estudios Andinos (IFEA, UMIFRE 17, CNRS-MAEE), miembro del Instituto Panamericano de Geografía e Historia del Ecuador. 
Desde la historiografía y la Historia, las categorías de tirano o héroe nacional con que se estigmatizó a Rumiñahui, fueron cuestionadas y desvirtuadas, con lo cual se produjo una ruptura con la tradición historiográfica, propuesta que fue desarrollada de forma parcial en mi libro Tras las huellas de Rumiñahui... (2003). De hecho los tres puntos suspensivos del título del libro no son inocentes: algo distinto y que no intuimos tramó Rumiñahui cuando asumió la resistencia indígena. A continuación desarrollaré un argumento no advertido por la historiografía que se relaciona con los símbolos que habría utilizado Rumiñahui para conducir esa complicada agenda, al margen de su gesta heroica, y que habrían legitimado su poder político en la defensa de la panaca de Atahualpa.

¿Cómo podía un hombre canalizar tanta autoridad en un panorama aterrador sin precedente en los Andes, caracterizado por el faccionalismo, la ambigüedad, el oportunismo y cuya población estaba acéfala?

Mi argumento es que Rumiñahui como producto historiográfico se desarrolló a partir de una escena concreta: la entrega del cuerpo de Atahualpa por parte de Cuxi Yupangue o Illescas a Rumiñahui. Si Rumiñahui, no recibía el cuerpo de su monarca, lo más probable es que habría pasado desapercibido como actor histórico: los Cronistas de Indias e historiadores oficiales no hubieran tenido al tirano que exterminó a la familia real y que robó los tesoros del Quito-Inca, en tanto que los ecuatorianos se hubieran quedado sin uno de sus héroes fundacionales de la patria.

Presumo que fue el empoderamiento simbólico de ese cuerpo lo que dio valor agregado a la actuación de Rumiñahui, quien habría utilizado la región de los Sigchos, ubicada en el flanco occidental de la actual provincia de Cotopaxi en el Ecuador, como el principal bastión de los incas quiteños en la resistencia contra los conquistadores españoles, por tres razones principales: población incondicional a su causa en una guerra asimétrica, infraestructura adecuada para la defensa y ataque y condiciones geográficas óptimas para el refugio.

\section{EL ACATAMIENTO DE RUMIÑAHUI AL CUERPO DE ATAHUALPA ¿UNA ILUSIÓN HISTORIOGRÁFICA?}

Cajamarca, sábado 26 de julio de 1533, el sol se ha puesto, en la plaza yace el cuerpo inerte del último gobernante cápac inca del Tahuantinsuyo: Atahualpa. Francisco Pizarro y sus hombres, a última hora le conmutaron la pena de la hoguera por la del garrote o la horca por haberse dejado «bautizar».

Poco antes de morir, Atahualpa imploró a Francisco Pizarro que velara por sus hijos y que su cuerpo fuera llevado al Quito-Inca para que fuera enterrado junto a su padre Huayna Cápac, cuyos restos mortales se dividieron entre Quito y el Cusco1.

1 Según Betanzos (1987 [1551-1557]: 207-209) el cuerpo de Huayna Cápac fue curado y llevado por sus parientes cercanos en unas andas al Cusco; no obstante, Atahualpa que se 
Los testigos presenciales de este trágico acontecimiento, Miguel de Estete, Cristóbal de Mena, Pedro Pizarro y Francisco de Xerez, coinciden en que el cuerpo de Atahualpa no fue quemado, sí fue velado durante la noche y enterrado al día siguiente en la iglesia del pueblo, en tanto que para Pedro Sancho de la Hoz, una parte de su carne y ropa fueron chamuscadas después de su muerte. La historia oficial de Francisco López de Gómara, redactada casi veinte años más tarde, concuerda con estos testimonios, pero se especifica que el cuerpo de Atahualpa fue llevado a Quito y entregado a Rumiñahui en Liribamba, antigua capital de los indios puruhaés. Entre finales y principios de los siglos XVI y XVII, Martín de Murúa aseveró que el cuerpo de Atahualpa fue desenterrado por el propio Rumiñahui y por Unanchillo2.

Corresponde a Juan de Betanzos la versión más depurada sobre la entrega del cuerpo de Atahualpa a Rumiñahui:

«Cuxi Yupangue... sacó el cuerpo de Atagualpa de la sepultura do[nde] estaba [iglesia del pueblo de Cajamarca] y púsolo en unas andas en las cuales le llevó de allí al Quito y estaba en el Quito en aquella sazón un capitán de Atagualpa que se decía Rumiñagui y como Cuxi Yupangue llevase el cuerpo de Atagualpa hízole un mensajero a este Rumiñagui por el cual le envió a decir como llevaba el cuerpo de su señor Atagualpa y como el Ruminagui tuviese esta nueva y viese que venía Cuxi Yupangue y que era señor y capitán general de Atagualpa y que traía su bulto y que llegado que fuese al Quito había de ser señor Cuxi Yupangue y él no propuso de le matar al Cuxi Yupangue como mejor pudiese y tomar el cuerpo de Atagualpa y ansi quedase como señor...». (Betanzos, 1987 [1551-1557]: 285-286)

Parte del suceso narrado por Betanzos a mediados del siglo XVI, fue retratado casi sesenta años más tarde por Guamán Poma de Ayala (1980 [1615-1616]: 117 [163]), en un sugestivo dibujo en el que se observa el asesinato cometido por Rumiñahui contra Illescas, que no es otro que el Cuxi Yupangue de Betanzos (fig. 1)3.

La información proporcionada por Betanzos es importante para el conocimiento del Quito-Inca, puesto que incorpora noticias que no se conocían hasta el año 1987, en que la crónica completa fue publicada por primera vez. La relatora de Betanzos fue Cuxirimay Ocllo, bautizada por los conquistadores españoles como doña Angelina, que a su vez fue hermana de Cuxi Yupangue y también una de las esposa de Atahualpa; entre ellos eran primos hermanos. Cuxirimay Ocllo

quedó en Quito, ordenó hacer ciertos bultos con cabellos, uñas y un pedazo de carne de su padre para realizar la fiesta de la Purucaya que se celebraba al año de su muerte. Véase también, Xerez (1985 [1534]: 118-119), Sarmiento de Gamboa (1942 [1572]: 108).

2 Véase, Estete (1968 [1535]: 387-388), Mena (1968 [1534]: 165-167), Pizarro (1978 [1571]: 63-64), Xerez (1985 [1534]: 155-156), Sancho de la Hoz (1968 [1534]: 280-281), López de Gómara (1946 [1552]: 234), Murúa (1987 [1611-1615]: 223). Unanchillo fue el cacique de Chillo conocido más como Quimbalimbo, véase Estupiñán Viteri (2003: 38).

3 Sobre la identidad de Cuxi Yupangue como Illescas, véase Estupiñán Viteri (2003: 44-55). 


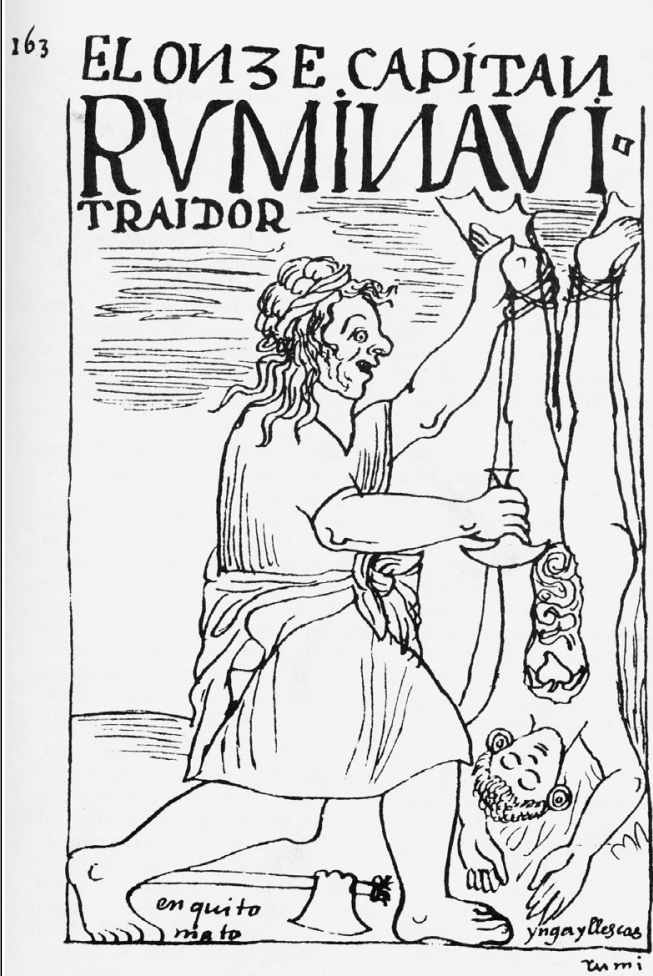

El once capitán, Rumiñaui, traidor / en Quito / mató Inga Illescns. 117

\section{Figura 1 - El capitán Rumiñahui}

Dibujo de Guamán Poma de Ayala estuvo presente en la captura de Atahualpa y después que este fue ejecutado, Francisco Pizarro la tomó para sí como su concubina. A la muerte de Pizarro, doña Angelina se casó con Juan de Betanzos y hay quienes escribieron que el lenguaraz de Felipillo se enamoró perdidamente de ella (Betanzos, 1987 [1551-1557]: 197-198, 272-273, 284; Cieza de León, 1997 [1553]: 174; Pizarro, 1978 [1571]: 62).

Según las prácticas de los incas, el cuerpo del monarca fallecido estaba dotado de poder, es una de las razones por las cuales era curado o momificado; este cuerpo llamado malqui- es el que daba origen a una nueva familia o panaca. También se elaboraban efigies conocidas como huauque que imitaban al Inca en vida o muerto, utilizando sus pelos, uñas y ropa y eran veneradas como si fueran el propio Inca o su doble. Cada panaca tenía la obligación de conservar el malqui y huauque de su Inca, a más de guardar sus haciendas, pertenencias y recuerdos personales; su compromiso era preservar en la memoria colectiva las hazañas de su progenitor para siempre. De hecho, el malqui del Inca era una genealogía viviente que conservaba sus propiedades, tierras, moradas o casas de recogimiento con criados o yanaconas que cuidaban de su cuerpo con devoción y cariño,

en tanto que sus mujeres, hijos, parientes y colaboradores cercanos le consultaban como si fuera un oráculo. También el malqui participaba en las ceremonias del Estado, sean éstas políticas o religiosas y el huauque era el principal emblema en las batallas. Hay que anotar, además, que entre momias se visitaban, costumbres que se mantuvieron en el Cusco hasta la década de 1570, en que el virrey Francisco de Toledo promovió la campaña de extirpación de idolatrías4.

Que el cuerpo de Atahualpa fue llevado a Quito y entregado a Rumiñahui, es un hecho bastante probable, pese a que no se han localizado hasta el presente

4 En las Crónicas de Indias, Historias Oficiales y documentos de archivo se encuentra información importante sobre la trascendencia que tenían el malqui y huauque de cada Inca reinante; no obstante en este avance de investigación — por razones de espaciohe realizado la síntesis inspirada en los siguientes trabajos: Alonso Sagaseta (1989), Curatola (2008), Doyle (1988), Farrington (1995), Guchte (1992), Hampe Martínez (2003), Hinojosa (1999), Isbell (1997), MacCormack (1990), Ziólwowski (1996). 
documentos específicos que respalden esta afirmación. Por ahora debemos dar crédito al relato que trasmitió la esposa de Atahualpa a Betanzos y también al discurso historiográfico que se generó a partir de este acontecimiento, aunque el énfasis se haya puesto en el «tesoro» material que acompañaba a los restos mortales, mas no en el significado alegórico que el cuerpo tenía entre los incas.

Mi hipótesis es que Rumiñahui fue el guardián del malqui de Atahualpa para preservar la tradición de la panaca, por eso rescató a los pequeños hijos y sus madres o esposas del monarca, casi en el acto de la captura y los trajo al QuitoInca. Con el tiempo uno de los vástagos debía fundar su propia panaca, práctica que se invocaba delante del malqui del padre fallecido. Si Atahualpa no aceptaba el bautizo, su cuerpo hubiera sido quemado y su panaca exterminada al no existir el símbolo esencial que legitimara la sucesión dinástica. Rumiñahui cuidó lo más que pudo de los hijos de Atahualpa y se sabe con certeza que el más importante y a quien hubiera correspondido la insignia real o mascapaycha, sobrevivió a la conquista española del Quito-Inca. Así lo demuestra la firma que estampó Francisco Topatauchi, el auqui o príncipe, en su testamento redactado en 1582 (Estupiñán Viteri, 1988).

También existen documentos de archivo y datos de los Cronistas de Indias sobre los hijos y esposas de Atahualpa que Rumiñahui llevó a la región de los Yumbos y de su cautiverio y saqueo que habría hecho Ruy Díaz, uno de los hombres fuertes del conquistador de Quito, Sebastián de Benalcázar. El atraco incluía ropa fina, preseas ricas, vasos y vasijas de oro y plata (Cieza de León, 1997 [1553]: 240; Estupiñán Viteri, 2003; Lippi, 2010)5. Posiblemente, las cosas que se robaron formaban parte de los bienes personales de Atahualpa y también de Huayna Cápac, pero en ese botín no estaban sus cuerpos secos6.

Rumiñahui, inmediatamente después de la ejecución de Atahualpa -a diferencia de Mango Inga - organizó una resistencia activa que no tranzó con los conquistadores españoles y que exigía firmeza en la toma de decisiones para enfrentar el desconcierto. Es en este contexto que el principal símbolo que podía investir a Rumiñahui de autoridad era el malqui de Atahualpa.

Otra conjetura se relaciona con el huauque de Atahualpa quien —al igual que su padre y sus antepasados incas - toda vez que fue investido con la mascapaycha en el palacio de Carangue, ordenó que se confeccione su bulto:

«[Atahualpa] se partió de allí [Carangue] y volvió a Quito donde llegado que fue tuvo nueva que sus capitanes Quizquis y Chalcuchima iban ya por las provincias de Bombom y Tarama... y teniendo esta nueva y se viese señor mandó luego hacer un bulto de sus mismas uñas y cabellos el cual imitaba a su persona y mandó que se llamase este bulto Ynga Guauquin que dice el hermano del Ynga y este bulto ansi hecho mandó que fuese puesto en unas andas y mandó a un criado suyo que se decia Chima que

5 La antigua nación de los Yumbos estaba asentada al noroccidente de la actual ciudad de Quito.

6 Betanzos (1987 [1551-1557]: 209). 
dando a este bulto que le sirviese y que tuviese cargo de guardarle y mirarle y dando este bulto otros muchos mozos y servicio mandó que luego fuese tomado el bulto y llevado en sus andas por la posta a do sus capitanes estaban Chalcuchima y Quizquiz para que las provincias y gentes que sujetasen diesen obediencia a aquel bulto en lugar de su persona... y ansi servían y respetaban a este bulto como si fuera allí en persona el mesmo Atahualpa...». (Betanzos, 1987 [1551-1557]: 220-221)7

El huauque de Atahualpa, una imagen a semejanza suya, no por el tamaño físico sino por su grandeza simbólica, tomó posesión cuando el aprisionamiento de Huáscar y la derrota de los incas cusqueños, cuya rendición se realizó frente al doble de su medio hermano:

«Al cabo, como se vieron tan pocos, y ésos tristes y quebrantados de tantas desdichas y vencimientos, acordaron de obedecer lo que se les mandaba y seguir su triste suerte, dando la obediencia a la figura de Atao Hualpa y a sus capitanes [Quisquis y Calicuchima]... que estaban esperando su última resolución. Así acordado, haciendo el semblante en la demostración más alegre que tenían el ánimo, con corazón afligido y triste, salieron por su orden, distinguiéndose en Ayllos [panacas]... Todos los que se habían hallado en la batalla donde fue preso Huascar Ynga llevaban una borla, en señal de que habían sido perdonados por los capitanes de Atao Hualpa del delito de haber peleado contra él. Llegados al Ilano de Quiuipay [Quipaypan] se fueron sentando por su orden en el suelo, haciendo reverencia o la mocha..., como ellos dicen, en señal de obediencia a la figura... de Atao Hualpa, que allí estaba». (Murúa, 1987 [1611-1615]: 194-195)

Las referencias hasta aquí presentadas abogan a favor de la primacía que habrían tenido el malqui y huauque de Atahualpa como signos de poder en la guerra de los incas quiteños contra el Cusco y posteriormente en la resistencia contra los conquistadores españoles.

Se podría inferir que Rumiñahui, amparado en estos símbolos dio respuestas correctas hasta la batalla en el páramo de Tiocajas, el principal evento militar y en el que — según Cieza de León- no hubo vencedores ni vencidos, pero los indios huyeron por la erupción del volcán de Latacunga: el Cotopaxi (Cieza de León, 1997 [1553]: 200-201)8. Rumiñahui —en su desasosiego-vaticinó que iba a vencer a los cristianos o viracochas, ese fue su compromiso, pero después de esta catástrofe natural perdió credibilidad y el ejército empezó a resquebrajarse. A partir de entonces, él y sus principales colaboradores optaron por el sistema de guerrilla, para lo cual el centro de operaciones habría sido la región de los Sigchos que fue incursionada por Topa Inga Yupangue y conquistada por Huayna Cápac, quien implantó colonias de mitimáes (Cabello Balboa, 1945 [1586]: 345-346)9.

7 Sobre el palacio de Carangue, véase Bray (2009).

8 Tiocajas está ubicado en la provincia de Chimborazo, Ecuador.

9 Sobre el impacto inca en los Sigchos, véase el importante trabajo de Salomon (1980); consúltese también Bray (2004). 
«En este pueblo [Latacunga] tenían los señores Ingas puesto mayordomo mayor: que tenía cargo de coger los tributos de las prouincias comarcanas, y recogerlos allí: donde assimismo auía gran cantidad de Mitimaes... que quiere significar Indios venidos de una tierra a otra... Y a estos Mitimaes mandavan los Ingas, que estuviessen siempre obedientes a lo que sus governadores y capitanes les mandassen: de tal manera que si los naturales se rebelassen, siendo ellos de parte del governador, eran luego castigados y reduzidos al servicio de los Ingas. Y por consiguiente, si los Mitimaes buscavan algún alboroto, eran apremiados por los naturales: y con esta industria tenían estos señores su imperio seguro que no se les rebelasse...». (Cieza de León, 1996 [1553]: 134-135)10

Más allá de la condición de los mitimáes como fuerza de choque en la guerra, es preciso rescatar su sentido de lealtad étnica y territorial. Subrayo que la guardia pretoriana de Atahualpa era atendida por mitimáes al mando de Rumiñahui y algunos como Ninanina y Rasoraso, también fueron víctimas del holocausto (Estupiñán Viteri, 2003) (fig. 2).

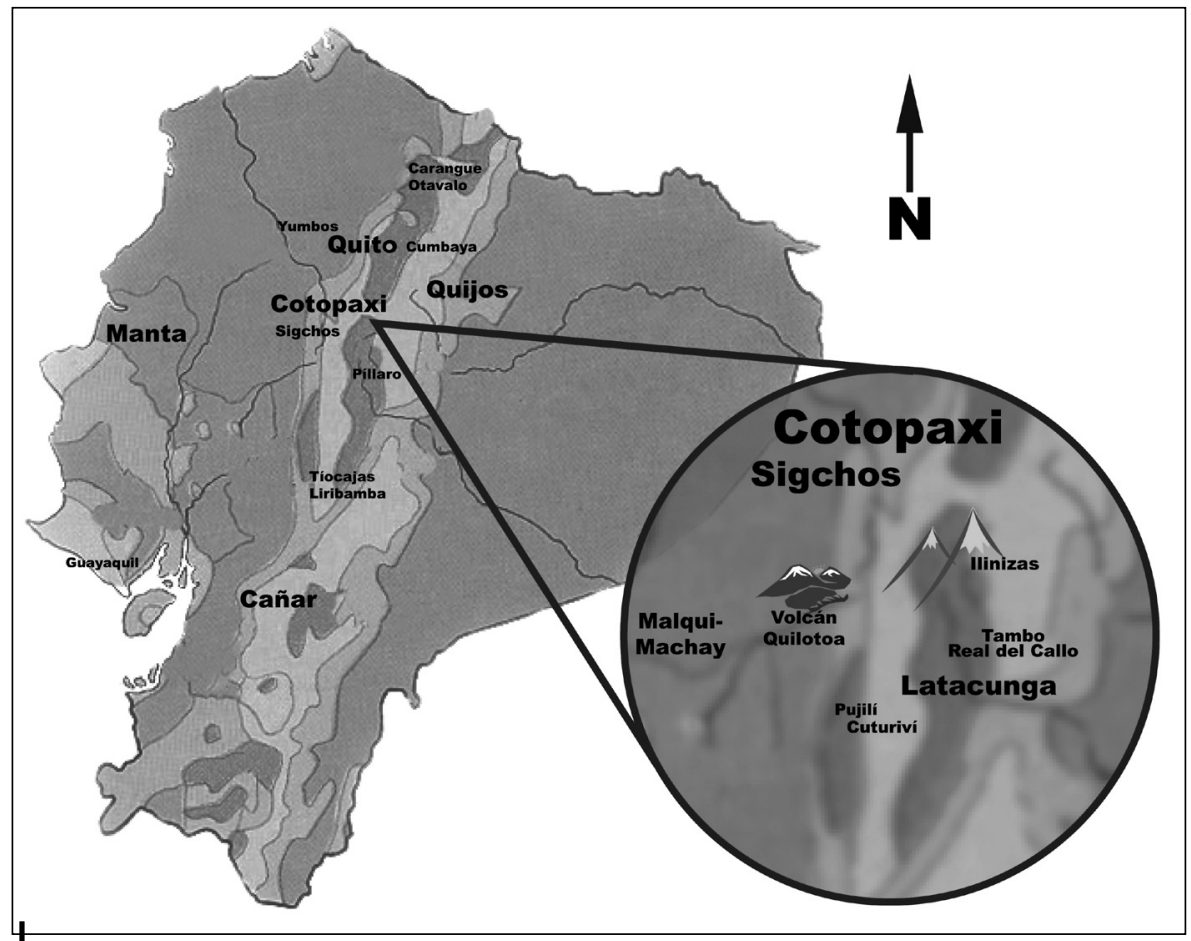

Figura 2 - El derrotero de la resistencia de los incas quiteños

10 Véase también, Guamán Poma de Ayala (1980 [1615-1616]: 82-83, 113). Latacunga es la capital de la provincia de Cotopaxi, jurisdicción a la que ha pertenecido la región de los Sigchos. 
Los Sigchos fue la región más segura para la resistencia de los incas quiteños, no solo por la presencia de recurso humano incondicional y combatiente, sino también porque tenía una extensa red de construcciones militares o pucarás que servían para la defensa y ataque, como lo ha registrado el arquéologo David Brown (2010). De otra parte, en el sector — cerca del volcán Cotopaxi y contiguo al camino real o Cápac Nan- se edificó en el Callo un tambo real de arquitectura imperial que servía para albergar a la élite inca y sus huestes, el que se vinculaba prestamente con los Sigchos.

Otro aspecto interesante se relaciona con las propiedades privadas que fueron de Atahualpa y que heredó su hijo Francisco Topatauchi, el auqui. La más extensa fue la de Cumbayá (más de 200 hectáreas) ubicada en el valle oriental de la actual ciudad de Quito y después la de Cuturiví (más de 100 hectáreas) circundante a Pujilí. También tenía otra cerca de los Ilinizas, pero se desconoce su extensión; los predios de Cuturiví y de los Ilinizas están en los límites de los Sigchos (Estupiñán Viteri, 1988).

La propiedad de Cuturiví es enigmática, pues hasta finales del siglo XVIII habría pertenecido a descendientes de la nobleza inca, como doña Isabel Tocto. En la actualidad, en las inmediaciones del cerro Cuturiví, existe un santuario en el que se venera al Divino Niño de Isinche, imagen que ha sido aderezada en alguna ocasión como el Inca y a quien los famosos danzantes de Pujilí, vestidos a la usanza de Vila Oma — el sumo sacerdote inca que peleó al lado de Mango Ingarinden honores ¿Acaso se trata de una representación de sincretismo cultural en las tierras privadas que fueron de Atahualpa? ${ }^{11}$

Poco antes de la hecatombe de la resistencia de los incas quiteños, los Sigchos conectó a sus principales protagonistas; «algo» había en el sector que demandaba la presencia de ellos: Rumiñahui fue capturado por los conquistadores españoles cuando salía huyendo de los Quijos (flanco oriental) hacia Sigchos (flanco occidental), en donde estaba previsto unirse con el gobernador del Quito-Inca -Zopozo Pangue- y con los mitimáes para hacer un frente común, mientras Quisquis con los huambracunas se dirigían hacia allá. Sin embargo, Quisquis en el trayecto y poco antes de llegar a los Sigchos, fue asesinado por un hermano de Atahualpa, Ilamado Huaynapalcón12.

\section{MALQUI-MACHAY, UN ENIGMA PARA LA ARQUEOLOGÍA}

Como escenario probabilístico sugiero que el malqui de Atahualpa fue llevado a los Sigchos después de los acontecimientos en los Yumbos (junio-julio de 1534),

11 Esta reflexión es objeto de una investigación complementaria que actualmente estoy realizando y que saldrá a la luz próximamente.

12 Véase Estupiñán Viteri (2003), cronología. Los huambracunas fueron los niños huérfanos que quedaron después de la matanza en Yahuarcocha y que posteriormente conformaron el grueso del ejército que acompañó a Quisquis en la guerra contra el Cusco, véase Cieza de León (1996 [1553]: 125-126). 
posiblemente por Zopozo Pangue - tío de Atahualpa y gobernador del QuitoInca- mientras Rumiñahui fue a buscar ayuda en los Quijos, pero le traicionaron el cacique de esa región y su cuñado llamado Tucomango, quien fungía como cacique de Latacunga y hasta ese momento habían sido parte de la resistencia de los incas quiteños 13 .

En este punto mi propuesta difiere de Salomon, para quien:

«Los guerreros indómitos del Tawantinsuyu se retiraron de los Yumbos hacia el oriente con el fin de proseguir el combate móvil. Pero una parte de la corte imperial, probablemente los no combatientes, se quedaron atrás protegidos por cierta ciudadela en las tierras bajas, de la cual el explorador Andrés Contero supo mientras viajaba sobre el curso superior del río Daule a unas 50 leguas $(210 \mathrm{~km})$ de Guayaquil: "la laguna donde dicen que estan recogidos ciertos Ingas que bajaron de Quito cuando entraron los españoles en la tierra"» (Salomon, 1980: 272).

Este pasaje de la historia es confuso, por lo que resulta difícil determinar quiénes podían ser o no ser combatientes, sin embargo, la referencia revierte especial importancia por la presencia de los incas que estaban recogidos en la laguna, la que sospecho es la del volcán Quilotoa —ubicada en términos de los Sigchos-y que era sagrada para los indios.

Los rumores sobre el movimiento de los incas quiteños eran certeros: los conquistadores españoles husmeaban con furia en la región, la paradoja es que los verdugos buscaban el tesoro del cuerpo, en tanto que para las víctimas el cuerpo era su mayor tesoro. En la Probanza del conquistador Diego de Sandoval —hombre animoso de Benalcázar - que fue redactada en 1539, a escasos cinco años del ajusticiamiento de Rumiñahui y sus colaboradores más cercanos, y cuando en la memoria colectiva estaban frescos los acontecimientos, se preguntó a los testigos lo siguiente:

«... si saben... que después, dende a ciertos días, el dicho capitán Sebastián de Benalcázar tuvo nuevas como el Quizquiz venía con mucho poder/ de indios a dar guerra al dicho capitán Sebastián de Benalcázar e a los que con él estaban, e a dar favor e ayuda a los caciques naturales destas partes para que no viniesen de paz, envió a llamar al capitán Diego de Tapia e a los que con él estaban, e fué a Píllaro e desde allí invió al capitán Juan Márquez con cierta gente detrás de las sierras de Latacunga a las provincias de Manta e haber e tomar ciertas fortalezas que estaban allí de mucha gente e caciques hechos fuertes...»14.

La relación entre la resistencia indígena y los símbolos que legitimaban sus acciones requerían de un espacio arquitectónico apropiado para tomar y promulgar

\footnotetext{
13 Véase Estupiñán Viteri (2003) cronología.

14 «Méritos y servicios: Diego de Sandoval: Perú, Nueva España, 1539», Archivo General de Indias, Patronato 93, n. ${ }^{\circ}$ 9, R. 3. En este artículo se ha utilizado la transcripción paleográfica del documento que fue publicada por Freile-Granizo (1964: 76, pregunta VIII); el resaltado es mío.
} 
decisiones que, sin lugar a dudas, demandaban de rituales complejos. Tratando de ser fiel a los movimientos de Rumiñahui, reconstruí su posible derrotero y opté por buscar rastros de aquel escenario físico que imanaba a la resistencia de los incas quiteños y que Benalcázar buscaba con ambición: descarté las guarniciones militares o pucarás, el tambo real del Callo y también las propiedades privadas de Atahualpa en Cuturiví y en los Ilinizas, por ser lugares no muy apartados de la ruta de los conquistadores españoles.

Encontré una pista clave en un documento inédito de finales del siglo XVI, en el que se registró que don Beltrán Castro y de la Cueva — cuñado de García Hurtado de Mendoza y Manrique, virrey del Perú- tenía concertados en el pueblo de Malqui noventa indios yungas y camayos que debían tributar mantas de algodón ${ }^{15}$. Casualmente el único topónimo Malqui que ubiqué en la ruta de Rumiñahui está en los Sigchos.

De otra parte, conforme a las averiguaciones que se realizaron por orden del virrey Toledo, los camayos eran los indios encargados de custodiar el cuerpo del Inca fallecido, así como sus pertenencias personales e ídolos (Toledo, 1920 [15701572]: 111). El principal extirpador de idolatrías, Cristóbal de Albornoz, coincide con esta acepción, pero, además, revela la función que habría tenido el camayo como garante de un tipo de trasmisión oral:

«... fuera de los mitimas y servicios quel inga dio a las dichas guacas, tienen otros servicios que llaman criados o camayos que sirven de guardar las dichas guacas y sus haziendas, fuera de los guardadores del ganado. En estos criados ban subcediendo los hijos y los nietos de los tales, e ansi no se pierde la memoria». (Albornoz, 1967 [1585]: 22)16

Una primera reflexión fue que el topónimo Malqui remitía al cuerpo de algún progenitor inca importante, en este caso podía ser Atahualpa, y que los camayos estaban fabricando mantas de algodón no solo para cumplir con su obligación tributaria, sino también para usos diferentes como amortajar el cuerpo periódicamente para evitar la descomposición, con lo cual el Inca seguía activo y como bien lo ha sugerido MacCormack, era inmortal y continuaba jugando un rol en los asuntos de los vivos (MacCormack, 1990: 20)17.

La relación de otro extirpador de idolatrías, Pablo de Arriaga, arroja datos complementarios y significativos:

«Después de estas huacas de piedra la mayor veneración y adoración es la de sus malquis... que son los huesos o cuerpos enteros de sus progenitores gentiles, que ellos dicen que son hijos de las huacas, los cuales tienen en los

15 «Concierto: Diego Valencia León con Jusepe Alcarraz, sobre el cobro de tributos de la encomienda de Beltrán de Castro y de la Cueva, en el pueblo de Malqui, 4/7/1597», Archivo Nacional, Quito, Escribanías Públicas, Protocolos, Notaría Primera, libro 6, Gaspar de Aguilar (escribano), folios 191v-192.

16 La cursiva es mía.

17 La traducción es mía. 
campos en lugares muy apartados, en los machays, que son sus sepulturas antiguas, y algunas veces los tienen adornados con camisetas muy costosas o de plumas de diversos colores o de cumbi. Tienen estos malquis sus particulares sacerdotes y ministros y les ofrecen los mismos sacrificios y hacen las mismas fiestas que a las huacas. Y suelen tener con ellos los instrumentos de que ellos usaban en vida: las mujeres husos y mazorcas de algodón hilado, y los hombres las tallas o lampas con que labraban el campo, o las armas con que peleaban... En estos malquis, como también en las huacas, tienen su vajilla para darles de comer y beber, que son mates, y vasos, unos de barro, otros de madera y algunas veces de plata y conchas de la mar». (Arriaga, 1968 [1621]: 203)18

La investigación que había realizado hasta ese momento — datos etnohistóricos relacionados con toponimia y topónimos geográficos vigentes - me obligó a dejar el «escritorio», para emprender la búsqueda de un lugar llamado Malqui: era como escarbar en más de 5000 kilómetros cuadrados en aquella región que fue poblada por mitimáes, la misma que escogió la resistencia de los incas quiteños como último refugio y que en el presente alberga a una población indígena vigorosa.

Fue así como el día sábado 16 julio de 2004, con Jaime Pástor Morris y la arqueóloga Tamara L. Bray, Ilegamos a una hacienda de nombre Malqui, ubicada en el trayecto «detrás de las sierras de Latacunga hacia el camino de Manta». En esta ocasión identificamos unos pocos vestigios arqueológicos incas que fueron como la pequeña punta de un iceberg, pues seis años más tarde y con mayor conocimiento sobre el tema, organicé una segunda expedición, a la que se unió el arqueólogo Eduardo Almeida Reyes. Nuevamente llegamos a Malqui y al día siguiente —sábado, 29 de junio de 2010 - a pocos kilómetros de esa hacienda, identificamos en una pequeña colina un sitio arqueológico inca único, de características peculiares y que nunca antes había sido registrado, el que — según sus moradores - desde tiempos inmemoriales se llama Machay...

No obstante que la investigación arqueológica está en una fase preliminar19, es evidente que se trata de un monumento inca de diseño imperial tardío con un portentoso callejón de ingreso (fig. 3) por el que se accede a varios aposentos rectangulares, estructuras construidas con piedra cortada y pulida y situadas alrededor de una plaza trapezoidal. El sitio está rodeado por acueductos y canales de agua (fig. 4), uno de los cuales conduce a una pequeña cascada que se desliza por la piedra hacia el baño del inca.

18 El resaltado y la cursiva son míos.

${ }^{19}$ La prospección arqueológica del sitio Malqui-Machay fue realizada por el arqueólogo Eduardo Almeida Reyes, entre el 24-30 de enero de 2011, referencia autorización del Instituto Nacional de Patrimonio Cultural de Ecuador n. ${ }^{\circ}$ 004-2010-R3. 


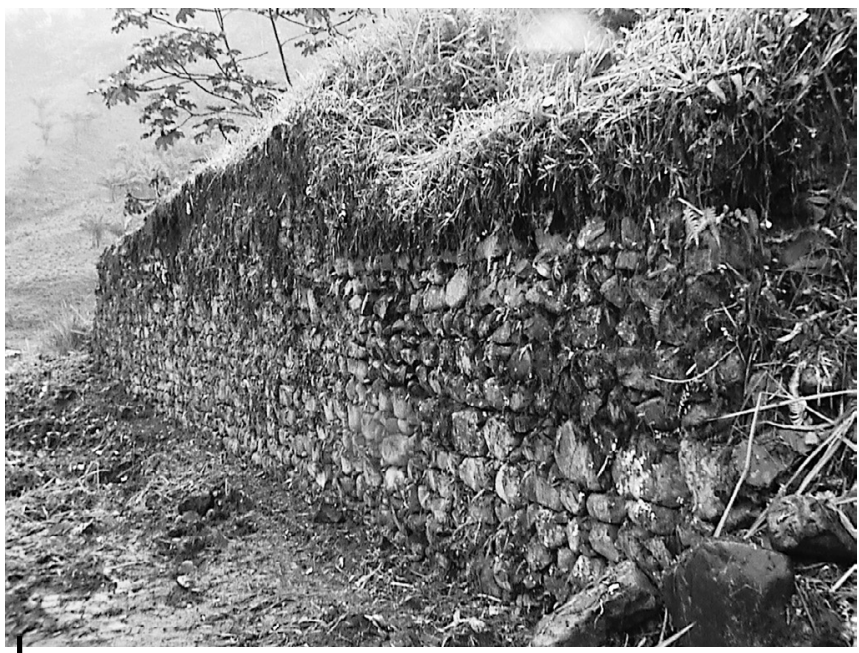

Figura 3 - Callejón de ingreso al sitio arqueológico Machay, antigua hacienda de Malqui (Los Sigchos)

Foto Jaime Pástor $M$.

Malqui-Machay, como hemos bautizado al monumento, cuya traducción literal del quechua o quichua al castelleno sería sepultura del cuerpo del progenitor del ayllu, más que respuestas presenta preguntas. iQue sea la arqueología la que ayude a descifrar este enigma!

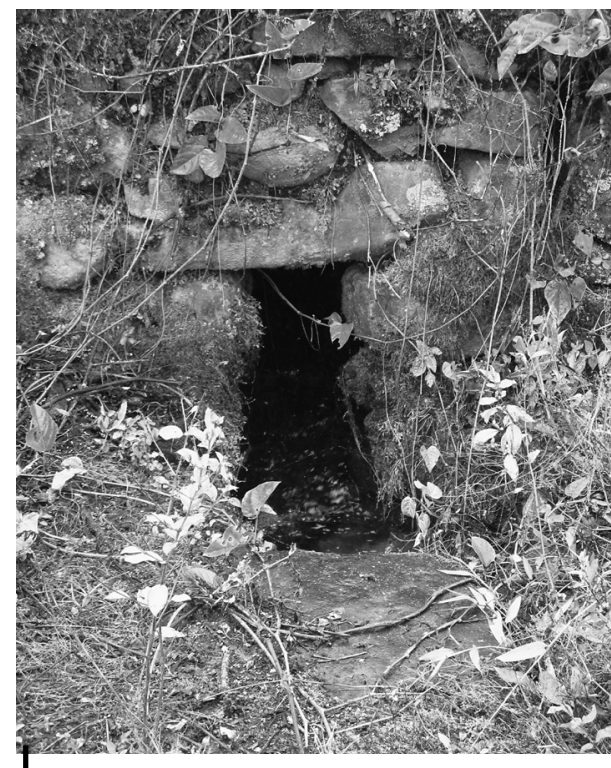

Figura 4 - Canal de agua en las ruinas arqueológicas de Machay

Foto Tamara L. Bray 
Los Sigchos, el último refugio de los incas quiteños. Un avance preliminar

\section{Referencias citadas}

ALBORNOZ, C. de., 1967 [1585] - La instrucción para descubrir todas las guacas del Pirú y sus camayos y haziendas. Journal de la Société des Américanistes (P. Duviols, ed.) LVI-1: 7-40; París.

ALONSO SAGASETA, A., 1989 - Las momias de los Incas: su función y realidad social. Revista Española de Antropología Americana, 19: 109-135; Madrid.

ARRIAGA, P. J., 1968 [1621] - Extirpación de la idolatría del Pirú. In: Crónicas peruanas de interés indígena (F. Esteve Barba, ed.), BAE, 209: 191-277; Madrid: Ediciones Atlas.

BETANZOS, J. de., 1987 [1551-1557] - Suma y narración de los incas, 317 pp.; Madrid: Ediciones Atlas. Prólogo, transcripción y notas por María del Carmen Martín Rubio,

BRAY, T., 2004 - A los bordes del imperio: los mitmaqkuna y la dinámica social en la frontera norte del Tawantinsuyu. Fase I: reconocimiento preliminar del área de Angamarca/Sigchos, provincia de Cotopaxi, 12 pp.; Quito: Informe presentado al Instituto de Patrimonio Cultural.

BRAY, T., 2009 - Saving the Palace of Atahualpa: The Late Imperial Site of Inca-Caranqui, Ecuador. Enlace internet: www.doaks.org/.../doaks_pco_project_grant_report_2008. html (28/04/2011).

BROWN, D. O., 2010 - Some observations on Inka Fortresses of Western Highland Ecuador, 7 pp. Enlace internet: http://revistas.arqueo-ecuatoriana.ec (28/04/2011).

CABELlO BALBOA, M., 1945 [1586] - Miscelánea Antártica, 451 pp.; Quito: Editorial Ecuatoriana.

CIEZA de LEÓN, P., 1996 [1553] - Crónica del Perú. Primera Parte, 354 pp.; Lima: PUCP. Introducción de F. Pease.

CIEZA de LEÓN, P., 1997 [1553] - Crónica del Perú. Tercera Parte, 441 pp.; Lima: PUCP. Edición, prólogo y notas de Francesca Cantú, vocabulario etimológico por Kurt Baldinger.

CURATOLA PETROCCHI, M., 2008 - La función de los oráculos en el Imperio Inca. In: Adivinación y oráculos en el mundo andino antiguo (M. Curatola \& M. Ziolkowski, eds.): 15-69; Lima: IFEA, PUCP.

DOYLE, M. E., 1988 - The ancestor cult and burial ritual in seventeenth and eighteen Century Central Peru, 308 pp.; Michigan, Ann Arbor, UMI films.Tesis doctoral.

ESTETE, M. de., 1968 [1535] - Noticia del Perú. Biblioteca Peruana, primera serie, 1: 345402; Lima.

ESTUPIÑÁN VITERI, T., 1988 - Testamento de don Francisco Atagualpa. Revista Miscelánea Histórica Ecuatoriana, 1: 8-67; Quito.

ESTUPIÑÁN VITERI, T., 2003 - Tras las huellas de Rumiñahui..., 162 pp.; Quito: Municipio del Distrito Metropolitano de Quito.

FARRINGTON, I. S., 1995 - The mummy, estate and palace of Inka Huayna Capac at Quispeguanca. Tawantinsuyu. Revista Internacional de Estudios Inkas, 1: 55-65; Australia.

FREILE-GRANIZO, J., 1964 - Probanza de Diego de Sandoval, 19.XI.1539, AGI, Patronato 93, No. 9, Ramo 3 (transcripción paleográfica). Revista Archivo Histórico del Guayas, 7: 73-104; Quito.

GUAMÁN POMA de AYALA, F., 1980 [1615-1616] - Nueva Corónica y Buen Gobierno, 434 pp.; Caracas. Transcripción, prólogo, notas y cronología por F. Pease, Biblioteca Ayacucho, tomo I. 
GUCHTE, M. Van de., 1992 - Sculpture and the concept of the double among the Inca kings. Anthropology and Aesthitics, 29-30: 256-268; Cambridge: Mass.

HAMPE MARTÍNEZ, T., 2003 - La última morada de los Incas: estudio históricoarqueológico del Real Hospital de San Andrés. Revista de Arqueología Americana (México, DF), 22: 101-135; México.

HINOJOSA CUBA, C., 1999 - Las momias de los Incas: El corazón de una tradición. Boletín de Lima, 116: 30-41; Lima.

ISBELL, W. H., 1997 - Mummies and mortuary monuments: a postprocessual prehistory of central Andean social organization, 371 pp.; Austin: University of Texas Press.

LIPPI, R. D., GUDIÑO, A. M., 2010 - Palmitopamba: yumbos e incas en el bosque tropical al noroeste de Quito (Ecuador). Bulletin de I'Institut Français d'Études Andines, 39 (3): 623-640.

LÓPEZ de GÓMARA, F., 1946 [1552] - Hispania Victrix. Primera y segunda parte de la Historia General de las Indias. In: BAE, 22: 155-294; Madrid. Colección dirigida e ilustrada por don Enrique de Vedia.

MACCORMACK, S., 1990 - Children of the sun and reason of state: myths, ceremonies and conflicts in Inca Peru, 35 pp.; Maryland: University of Maryland, College Park.

MENA, C. de., 1968 [1534] - La conquista del Perú [El anónimo sevillano]. Biblioteca Peruana, primera serie, 1: 133-169; Lima.

MURÚA, M. de., 1987 [1611-1615] - Historia General del Perú, 583 pp.; Madrid: Edición de Manuel Ballesteros, Historia 16.

PIZARRO, P., 1978 [1571] - Relación del Descubrimiento y conquista del Perú, 277 pp.; Lima: PUCP. Edición de Guillermo Lohmann Villena y nota de Pierre Duviols.

SALOMON, F., 1980 - Los señores étnicos de Quito en la época de los incas, 322 pp.; Otavalo: Instituto Otavaleño de Antropología. Pendoneros 10.

SANCHO de la HOZ, P., 1968 [1534] - Relación para su Majestad. Biblioteca Peruana, primera serie, 1: 277-343; Lima.

SARMIENTO de GAMBOA, P., 1942 [1572] - Historia de los Incas, 199 pp; Buenos Aires: Emecé. Colección Hórreo 10.

TOLEDO, F. de., 1920 [1570-1572] - Relación sumaria de lo que se contiene en la información de la tiranía de los Ingas. In: Informaciones sobre el Antiguo Perú $(\mathrm{H}$. H. Urteaga, ed.): 103-144; Lima: Colección de libros y documentos referentes a la Historia del Perú, tomo III, segunda serie.

XEREZ, F. de., 1985 [1534] - Verdadera Relación de la Conquista del Perú, 207 pp.; Madrid: Edición de Concepción Bravo, Historia 16.

ZIÓLOWSKI, M. S., 1996 - La guerra de los Wawqi. Los objetivos y los mecanismos de la rivalidad dentro de la élite inka, siglo XVI-XVI, 425 pp.; Quito: ABYA-YALA. 